\title{
Serum thyroglobulin determination in the follow-up of patients with differentiated thyroid carcinoma
}

\author{
Martin Schlumberger and Eric Baudin \\ Institut Gustave-Roussy, 39 Rue Camille Desmoulins, 94805 Villejuif Cedex, France \\ (Correspondence should be addressed to M Schlumberger)
}

Thyroglobulin $(\mathrm{Tg})$ is produced only by thyroid follicular cells. Following total thyroid ablation, it should be undetectable in serum and any detectable level then indicates the persistence or recurrence of neoplastic disease. This is the basis for the use of $\mathrm{Tg}$ as a postoperative tumor marker in the follow-up of thyroid cancer patients (1). The aim of follow-up is the early detection of persistent or recurrent disease, and this is made possible by the combined use of sensitive $\mathrm{Tg}$ measurement, neck ultrasound and a ${ }^{131}$ I total body scan (TBS) $(2,3)$.

The results of $\mathrm{Tg}$ measurement are highly dependent on the method used. This paper therefore focuses first on the methods used for the measurement of serum $\mathrm{Tg}$ level and then analyzes results obtained during the follow-up of patients with differentiated thyroid carcinoma, mainly based on experience at the Institut Gustave-Roussy, Villejuif, France.

\section{Limitations of serum Tg measurement}

The first method for routine measurement of serum $\mathrm{Tg}$ level was described in 1973 by Van Herle et al. (1). It was a competitive radioimmunoassay (RIA) using rabbit polyclonal anti-Tg antibodies. Functional sensitivity was $3-5 \mathrm{ng} / \mathrm{ml}$, which at that time and for this technique was considered as excellent.

Since the mid 1980s, immunoradiometric assays (IRMAs) using monoclonal anti-Tg antibodies have been available. IRMAs are currently considered as reference methods and are routinely used in almost all European centers. Functional sensitivity was $1-2 \mathrm{ng} / \mathrm{ml}$ and correlation with previous RIAs was excellent in sera in which there was no interference in the assay. Since 1994, the functional sensitivity of IRMA methods has improved to less than $1 \mathrm{ng} / \mathrm{ml}(4,5)$. However, the clinical significance of some of these highly sensitive IRMAs becomes questionable either because intra- and interassay precision is not stable enough from batch to batch, or because non-specific effects in the assay system lead to a large number of detectable, although low, Tg values that do not correspond to the clinical history or actual situation of the patients.

Efforts made towards the standardization of $\mathrm{Tg}$ measurements (6) have succeeded in only partly reducing the differences between assays, and so comparisons of results obtained with different assays will continue to pose difficulties.

Serum $\mathrm{Tg}$ auto-antibodies $(\mathrm{Tg} \mathrm{Ab})$ are found in at least $15 \%$ of patients with differentiated thyroid carcinoma, and can alter the results of $\mathrm{Tg}$ determinations. Serum should be screened for $\mathrm{Tg} \mathrm{AB}$ with a sensitive $\mathrm{Tg}$ $\mathrm{Ab}$ immunoassay before $\mathrm{Tg}$ measurement is undertaken. As an alternative, a recovery test has been advocated, in parallel with each $\mathrm{Tg}$ determination. It consists of adding a known amount of $\mathrm{Tg}$ to the serum sample and measuring the recovery; it distinguishes sera with interference (recovery $<70-80 \%$ ) and those without interference (recovery $>70-80 \%$ ). The consequences of interference depend upon the method used for $\mathrm{Tg}$ measurement. In RIAs, the importance and nature of the interference are not predictable; they may cause over- or underestimation of serum Tg concentrations. Some of the modern IRMAs, using monoclonal antibodies with high binding constants and incubation steps of more than only a few hours, often allow $\mathrm{Tg}$ immune extraction from weakly bound endogeneous $\mathrm{Tg}-\mathrm{Tg} \mathrm{Ab}$ complexes to occur. In these IRMAs, interference is found in approximately $1 \%$ of sera from thyroid cancer patients and causes only an underestimate. Therefore, in the presence of interference, any detectable $\mathrm{Tg}$ level indicates the presence of thyroid tissue; however, when $\mathrm{Tg}$ is undetectable a degree of caution is advisable in the presence of $\mathrm{Tg} \mathrm{Ab}$ even if the recovery test is normal (7).

From a clinical point of view, $\mathrm{Tg} \mathrm{Ab}$ are sought at the first $\mathrm{Tg}$ determination, preferably by using an RIA method. In their absence, only a recovery test is performed on each subsequent $\mathrm{Tg}$ determination. The recovery test is also necessary to detect falsely low $\mathrm{Tg}$ values due to the high-dose hook effect, which unfortunately occurs rather early in some assays; furthermore, it is helpful to disclose non-specific effects like human anti-mouse antibody interference. If present, $\mathrm{Tg} \mathrm{Ab}$ should be sought at each subsequent $\mathrm{Tg}$ determination.

\section{Serum Tg determination during the follow-up of thyroid cancer patients}

The clinical value of serum Tg determination by IRMAs has been evaluated in large series of thyroid cancer 
patients in whom $\mathrm{Tg} \mathrm{Ab}$ were not detected or who had a normal recovery test. Furthermore, a few studies of long-term follow-up of patients using sequential $\mathrm{Tg}$ determinations have been reported $(4,8-10)$.

$\mathrm{Tg}$ is produced by both normal and tumoral thyroid tissues; the serum level increases following thyroidstimulating hormone (TSH) stimulation by a factor of at least four in patients with neoplastic disease $(4,5,8-12)$. Therefore, these studies have been performed in two situations: during L-thyroxine (LT4) treatment and following LT4 withdrawal, with the knowledge of the presence or absence of non-tumoral thyroid remnants.

\section{Patients with neoplastic disease}

Clinical data During LT4 treatment, the serum Tg level is related to tumor burden and is elevated in almost all patients with metastases visible on standard X-rays; hence, X-rays are not indicated in patients with undetectable Tg levels. It is lower in those with distant metastases not visible on standard X-rays, and low in most patients with isolated lymph node metastases. In this situation, the $\mathrm{Tg}$ level is undetectable in less than $1 \%$ of patients with distant metastases visible on X-rays, in $5 \%$ of patients with lung metastases not visible on X-rays, and in $20 \%$ of patients with isolated lymph node metastases $(3-5)$.

Following thyroid hormone withdrawal, the Tg level is increased in almost all patients with distant metastases, even if these are not visible on X-rays. Similarly, $\mathrm{Tg}$ is detectable in almost all patients with isolated lymph node metastases, and its level is frequently high. Therefore, TSH secretion stimulated by LT4 withdrawal increases the sensitivity of $\mathrm{Tg}$ measurement for the detection of neoplastic tissue.

Cases of patients with metastases and undetectable $\mathrm{Tg}$ levels while off LT4 treatment have been reported. Some of these patients had small tumor deposits, for instance small lymph node metastases, and the undetectable $\mathrm{Tg}$ levels may be due to a lack of sensitivity of the method used for $\mathrm{Tg}$ measurement or to interference. Rarely, an absence of $\mathrm{Tg}$ production by the neoplastic tissue or the production of an abnormal $\mathrm{Tg}$, not detected by the monoclonal antibodies used in the assay, has been postulated.

Positive predictive value When Tg measurement was introduced into routine practice, $13 \%$ of patients were found to have detectable $\mathrm{Tg}$ levels following total thyroid ablation, and no other evidence of disease, including a negative TBS with a diagnostic dose of ${ }^{131} \mathrm{I}(13-15)$. In $80 \%$ of these patients with a $\mathrm{Tg}$ level above $10 \mathrm{ng} / \mathrm{ml}$ during LT4 treatment and above $40 \mathrm{ng} / \mathrm{ml}$ following LT4 withdrawal, a ${ }^{131} \mathrm{I}$ TBS performed with $100 \mathrm{mCi}$ revealed uptake in the thyroid bed, lymph nodes or at distant sites (14-16). In the other patients, metastases without any ${ }^{131}$ I uptake became clinically detectable some years later. These data clearly show that these detectable Tg levels should not be considered as falsely positive, provided that $\mathrm{TSH}$-stimulated $\mathrm{Tg}$ levels are clearly above the corresponding value on LT4 treatment.

In the initial studies, only RIA methods were available. Thereafter, with the availability of sensitive IRMA methods, the decision levels for a highly sensitive ${ }^{131} \mathrm{I}$ TBS with $100 \mathrm{mCi}$ have been decreased to $5 \mathrm{ng} / \mathrm{ml}$ during LT4 treatment and between 10 and $40 \mathrm{ng} / \mathrm{ml}$ following LT4 withdrawal (depending on prognostic factors and on the clinical likelihood of persistent or recurrent disease), and to patients with a gradual increase in $\mathrm{Tg}$ levels (17). It should be recalled that when the $\mathrm{Tg}$ level is close to the limit of sensitivity of the assay method, TSH stimulation obtained after thyroid hormone withdrawal significantly increases its level; only the absence of significant increase in this situation would identify false positive values.

At the present time, fewer than $2 \%$ of patients considered to be in complete remission after total thyroid ablation have detectable Tg level during LT4 treatment. This decrease in the number of patients with detectable $\mathrm{Tg}$ level is related to the use of sensitive IRMA methods and to more complete initial treatments and also to the more frequent use of highly sensitive ${ }^{131}$ I TBS with $100 \mathrm{mCi}$. In fact, a recent study compared $\mathrm{Tg}$ levels off LT4 treatment and post-ablative ${ }^{131}$ I TBS in patients who had undergone a total thyroidectomy: post-ablative ${ }^{131}$ I TBS showed ectopic uptake in $11 \%$ of patients with $\mathrm{Tg}$ levels below $5 \mathrm{ng} / \mathrm{ml}$, in $24 \%$ of those with $\mathrm{Tg}$ levels ranging from 6 to $15 \mathrm{ng} / \mathrm{ml}$, and in $46 \%$ of those with Tg levels above $15 \mathrm{ng} / \mathrm{ml}$ (18). These data clearly show that a TBS should be routinely performed after the administration of a high dose of ${ }^{131} \mathrm{I}$.

\section{Patients without detectable disease}

Clinical data After total thyroid ablation (by total thyroidectomy and ${ }^{131} \mathrm{I}$ ablation), the Tg level during LT4 treatment is undetectable in $98 \%$ of patients, being low $(<5 \mathrm{ng} / \mathrm{ml})$ in the others. Following thyroid hormone withdrawal, the $\mathrm{Tg}$ level remains undetectable in $90 \%$ of these patients, being detectable at a low level $(<10 \mathrm{ng} / \mathrm{ml})$ in the others $(4,5)$.

After total (or subtotal) thyroidectomy only, the Tg level is undetectable in $93 \%$ of the patients during LT4 treatment, and in $80 \%$ of them following thyroid hormone withdrawal. These data show that ${ }^{131} \mathrm{I}$ ablation slightly increases the specificity of Tg measurement by ablating non-tumoral thyroid remnants; also, it permits a post-ablative ${ }^{131}$ I TBS that may reveal metastatic uptake in some patients with detectable Tg levels.

It must be noted that the Tg level may remain detectable for some weeks after initial surgery, and when detectable it should be taken into account only if measured more than 3 months after initial surgery. 
After lobectomy, the Tg level is undetectable during LT4 treatment in only half of the patients. In the majority of patients with detectable Tg levels, ultrasound examination of the remnant lobe has shown clinically unsuspected micronodules; due to their small size, fine needle biopsy may be impossible and in case of progression, surgery may be warranted. These data favor a subtotal or total thyroidectomy in all patients with differentiated thyroid carcinoma. Following thyroid hormone withdrawal, the $\mathrm{Tg}$ level is poorly informative in these patients, because it can be produced both by normal and by neoplastic thyroid tissue.

Negative predictive value Among patients with undetectable Tg levels following LT4 withdrawal more than 2 years after initial treatment, long-term follow-up showed a relapse in fewer than $1 \%$. An undetectable Tg level in this situation is therefore an excellent criterion of cure. In these patients, LT4 treatment is aimed at maintaining euthyroidism, with a low to normal or slightly subnormal but not suppressed TSH level, and any other test is unnecessary as long as $\mathrm{Tg}$ remains undetectable.

However, a relapse was observed in $10 \%$ of patients with undetectable Tg level during LT4 treatment, and a detectable $\mathrm{Tg}$ level off treatment more than 2 years after initial treatment. In such patients, we advocate a ${ }^{131} \mathrm{I}$ TBS with $100 \mathrm{mCi}$ if the Tg level is above $40 \mathrm{ng} / \mathrm{ml}$ off LT4 treatment. If negative, LT4 treatment is maintained at suppressive doses, and another ${ }^{131}$ I TBS performed with $100 \mathrm{mCi}$ only if it becomes detectable during LT4 treatment.

In many patients with relatively low Tg levels, the relapse was localized to the neck, and could often be demonstrated by high resolution ultrasonography, and fine needle biopsy with cytology, and in doubtful cases by $\mathrm{Tg}$ measurement in the biopsy fluid (19).

\section{Conclusion}

$\mathrm{Tg}$ measurement is a highly specific and sensitive test for the follow-up of thyroid cancer patients, if appropriately selective assay systems are used. In doubtful cases, TSH stimulation provoked by LT4 withdrawal is advocated. In the near future, the availability of recombinant human TSH will permit the stimulation of Tg production, while avoiding symptoms of hypothyroidism (20). In patients with detectable Tg levels, a ${ }^{131}$ I TBS with $100 \mathrm{mCi}$ will frequently reveal the origin of $\mathrm{Tg}$ production. High resolution ultrasonography is currently used to reveal neck lymph nodes in patients at risk of a local recurrence. In the majority of patients, undetectable Tg levels off LT4 treatment indicate cure of the disease and allow for LT4 treatment at replacement dose while obviating the need for any other test to be performed.

\section{References}

1 Van Herle AJ, Uller RP, Matthews NL \& Brown J. Radioimmunoassay for measurement of thyroglobulin in human subjects. Journal of Clinical Investigation 197352 1320-1327.

2 Coburn M, Teates D \& Wanebo HJ. Recurrent thyroid cancer: role of surgery versus radioactive iodine (I-131). Annals of Surgery $1994219587-595$.

3 Schlumberger M, Challeton C, De Vathaire F, Travagli JP, Gardet P, Lumbroso JD et al. Radioactive iodine treatment and external radiotherapy for lung and bone metastases from thyroid carcinoma. Journal of Nuclear Medicine 199637 598-605.

4 Schlumberger M. Fragu P, Gardet P. Lumbroso J, Violot D \& Parmentier C. A new immunoradiometric assay (IRMA) system for thyroglobulin measurement in the follow-up of thyroid cancer patients. European Journal of Nuclear Medicine 199118 153-157.

5 Schlumberger M \& Pacini F. Tumeurs de la Thyroide, p 351. Paris: Nucleon, 1997.

6 Feldt-Rasmussen U, Profilis C, Colinet E, Black E, Bornet H, Bourdoux $\mathrm{P}$ et al. Human thyroglobulin reference material (CRM 457). Annales de Biologie Clinique $199654337-342$ and 343-348.

7 Mariotti S, Barbesino C, Caturegli P, Marino M, Manetti L, Pacini F et al. Assay of thyroglobulin in serum with thyroglobulin autoantibodies: an unobtainable goal? Journal of Clinical Endocrinology and Metabolism $199580468-472$.

8 Pacini F, Lan R, Mazzeo S, Grasso L, Taddei D \& Pinchera A. Diagnostic value of a single serum thyroglobulin determination on and off thyroid suppressive therapy in the follow-up of patients with differentiated thyroid cancer. Clinical Endocrinology 198523 405-411.

9 Girelli ME, Busnardo B, Ameno R, Casara D, Betterle C \& Piccolo M. Critical evaluation of serum thyroglobulin (Tg) levels during thyroid hormone suppression therapy versus Tg levels after hormone withdrawal and total body scan: results in 291 patients with thyroid cancer. European Journal of Nuclear Medicine $198611333-335$.

10 Black EG, Sheppard MC \& Hoffenberg R. Serial serum thyroglobulin measurements in the management of differentiated thyroid carcinoma. Clinical Endocrinology 198725 115-120.

11 Schlumberger M, Charbord P, Fragu P, Lumbroso J, Parmentier C \& Tubiana M. Circulating thyroglobulin and thyroid hormones in patients with metastases of differentiated thyroid carcinoma: relationship to serum thyrotropin levels. Journal of Clinical Endocrinology and Metabolism 198051 513-519.

12 Schlumberger M. Can iodine-131 whole body scan be replaced by thyroglobulin measurement in the post-surgical follow-up of differentiated thyroid carcinoma. Journal of Nuclear Medicine 1992 $33172-173$.

13 Ashcraft MW \& Van Herle AJ. The comparative value of serum thyroglobulin measurements and iodine-131 total body scans in the follow-up study of patients with treated differentiated thyroid cancer. American Journal of Medicine 1981 71 806-814.

14 Pacini F, Lippi F, Formica N, Elisei R, Anelli S, Ceccarelli C \& Pinchera A. Therapeutic doses of iodine-131 reveal undiagnosed metastases in patients with detectable serum thyroglobulin levels. Journal of Nuclear Medicine 198728 1888-1891.

15 Schlumberger M, Arcangioli 0, Piekarski JD, Tubiana M Parmentier C. Detection and treatment of lung metastases of differentiated thyroid carcinoma in patients with normal chest X-rays. Journal of Nuclear Medicine 198829 17901794.

16 Pineda JD, Lee T, Am K, Reynolds JC \& Robbins J. Iodine-131 therapy for thyroid cancer patients with elevated thyroglobulin and negative diagnostic scan. Journal of Clinical Endocrinology and Metabolism 199580 1488-1492.

17 Schlumberger M, Mancusi F, Baudin E \& Pacini F. ${ }^{131}$ I therapy for elevated thyroglobulin levels. Thyroid 19977 273-276.

18 Tenenbaum F, Corone C, Schlumberger M \& Parmentier C. Thyroglobulin measurement and post-ablative iodine-131 total 
body scan after total thyroidectomy for differentiated thyroid carcinoma in patients with no evidence of disease. European Journal of Cancer 1996321262.

19 Pacini F, Fugazzola L, Lippi F, Ceccarelli C, Centoni R, Miccoli P et al. Detection of thyroglobulin in fine needle aspirates of nonthyroidal neck masses: a clue to the diagnosis of metastatic differentiated thyroid cancer. Journal of Clinical Endocrinology and Metabolism 199274 1401-1404.
20 Meier CA, Braverman LE, Ebner S, Veronikis I, Daniels GH, Ross DS et al. Diagnostic use of recombinant human thyrotropin in patients with thyroid carcinoma (phase I/II study). Journal of Clinical Endocrinology and Metabolism 199473 188-196.

Received 29 May 1997

Accepted 29 August 1997 